\title{
Role of T Lymphocyte Subsets in the Pathogenesis of Primary Infection and Rechallenge with Respiratory Syncytial Virus in Mice
}

\author{
Barney S. Graham, * Lori A. Bunton," Peter F. Wright," and David T. Karzon* \\ Departments of ${ }^{*}$ Medicine and ${ }^{\ddagger}$ Pediatrics, Vanderbilt University School of Medicine, Nashville, Tennessee 37232
}

\begin{abstract}
The role of CD4+ and CD8 + T lymphocytes in terminating respiratory syncytial virus (RSV) replication, causing disease, and protecting from reinfection was investigated using a BALB/c mouse model in which CD4+ or CD8+ lymphocytes or both were depleted by injections of Mab directed against the respective mouse lymphocyte determinants. Kinetics of RSV replication, illness, and pathology were assessed after primary infection and rechallenge. Both CD4+ and CD8+ lymphocyte subsets were involved in terminating RSV replication after primary infection. When both $T$ lymphocyte subsets were depleted RSV replication was markedly prolonged, yet no illness was evident, suggesting that host immune response rather than viral cytocidal effect was the primary determinant of disease in mice. Both CD4+ and CD8+ lymphocytes contributed to illness, although CD8+ lymphocytes appeared to play the dominant role in this particular system. Analysis of histological responses suggested that CD4+ lymphocytes were required for the appearance of peribronchovascular lymphocytic aggregates seen in normal mice after rechallenge, and that the presence of alveolar lymphocytes was correlated with illness. It is postulated that antibody is an illness-sparing mechanism for protecting mice from RSV infection, and that $T$ lymphocytes are an important determinant of illness. Further delineation of RSVinduced immunopathogenesis in primary infection and reinfection will provide important information for the development of vaccine strategies. (J. Clin. Invest. 1991. 88:1026-1033.) Key words: pathogenesis $\bullet$ bronchiolitis • pneumonia • antibody • immunodeficiency
\end{abstract}

\section{Introduction}

Respiratory syncytial virus (RSV) ${ }^{1}$ is an important cause of respiratory illness in children and adults. Our incomplete understanding of the immunopathogenesis of RSV-induced disease is a major impediment to the evaluation of new $R S V$ vaccine candidates in seronegative infants. We have therefore de-

This work was partially presented in abstract form, AFCR, Washington, DC, Clin. Res. 1989. 37:429.

Address correspondence and reprint requests to Dr. Barney S. Graham, Department of Medicine, A-3310 MCN, Vanderbilt University School of Medicine, Nashville, TN 37232.

Received for publication 12 December 1990 and in revised form 23 May 1991.

1. Abbreviations used in this paper: LCMV, lymphocytic choriomeningitis virus; RSV, respiratory syncytial virus.

J. Clin. Invest.

(c) The American Society for Clinical Investigation, Inc.

$0021-9738 / 91 / 09 / 1026 / 08 \quad \$ 2.00$

Volume 88, September 1991, 1026-1033 veloped a system to begin defining the determinants of pathology and illness in RSV-infected mice. After primary RSV infection mice demonstrate illness, immune-mediated lung pathology, and high titers of RSV in lung and nose (1). RSV rechallenge in the model is similar to that in man. RSV is able to replicate in the nose, but not in the lower respiratory tract, of mice rechallenged more than 16 mo after primary infection (2). Data derived from B cell-depleted mice suggested that humoral responses were not important for terminating RSV replication after primary infection, that only partial protection from reinfection was achieved in the absence of RSVspecific antibody, and that illness was enhanced in both primary infection and on rechallenge in the absence of RSV-specific antibody (2a). The objectives of the current studies were to determine the role of $\mathrm{T}$ lymphocyte subsets in termination of RSV replication, recovery from primary infection, and protection from reinfection.

\section{Methods}

Mice. Pathogen-free female BALB/c mice were purchased from Charles River Laboratories (Raleigh, NC). Retired breeders (8-10-moold) were used in all experiments. They were shipped in filtered crates and housed in a Duo-flo laminar flow unit (Lab Products Inc., Maywood, NJ) remote from the central animal facility. Cages, bedding, food, and water were sterilized before use. Room temperature was maintained at $27^{\circ} \mathrm{C}$ and a 12 -h-on, 12-h-off light cycle was provided. In caring for animals the investigators adhered to the "Guide for the Care and Use of Laboratory Animals" prepared by the Committee on Care and Use of Laboratory Animals of the Institute of Laboratory Animal Resources, National Research Council, National Institutes of Health (Bethesda, MD).

Cells and virus. HEp-2 cells were maintained in Eagle's minimal essential media supplemented with glutamine, amphotericin, gentamicin, penicillin G, and $10 \%$ fetal bovine serum (10\% EMEM). The A2 strain of RSV was provided by Dr. Robert Chanock, National Institutes of Health. Working stocks of the virus were prepared as previously described (1) and maintained titers in the range of $10^{8} \mathrm{pfu} / \mathrm{ml}$ for over 6 mo at $-70^{\circ}$.

Antibody. Productive clones of hybridomas GK1.5, 2.43, and $\mathrm{HB} 151$ were used to make ascites in BALB/c nu/nu mice. GK1.5 is a rat $\mathrm{IgG}_{2 \mathrm{~b}}$ MAb specific for L3T4, the CD4 determinant for mouse lymphocytes (3). Hybridomas 2.43 (4), and ATCC \#HB151 make monoclonal antibodies against Lyt2 (CD8), and human HLA-Dr5, respectively. The hybridomas were a gift from Steven Martin, University of Tennessee at Knoxville. Ascites was produced in (nu/nu) BALB/c mice exposed to 450 total body rads and primed with pristane. Total protein and albumin concentrations were quantitated using a Multistat III Microcentrifugal Analyzer (Instrumentation Laboratory, Lexington, MA). Serum protein electrophoresis was performed with a Titan Gel high resolution REP SP-30 kit (Helena Laboratories, Beaumont, TX) and the gamma globulin fraction was determined by densitometry with an Electrophoresis Data Center (Helena Laboratories). Ascites fluid was diluted in PBS to $500 \mu \mathrm{g}$ of immunoglobulin per milliliter before injection.

Immunodepletion of mice. CD4+, CD8+, both, or no lymphocyte subsets were depleted in mice by treatment with GK1.5, 2.43, both, or 


\begin{tabular}{|c|c|c|c|c|c|c|c|c|}
\hline \multirow{3}{*}{$\begin{array}{l}\text { Depletion } \\
\text { MAb }\end{array}$} & \multirow[b]{3}{*}{ Target } & \multirow{3}{*}{$\begin{array}{l}\text { Lymphocyte } \\
\text { subset } \\
\text { depleted }\end{array}$} & \multicolumn{6}{|c|}{ Status of immune function ${ }^{\ddagger}$} \\
\hline & & & \multicolumn{3}{|c|}{$\begin{array}{c}\text { Primary infection and rechallenge } \\
\text { Design 1 }\end{array}$} & \multicolumn{3}{|c|}{$\begin{array}{l}\text { Rechallenge } \\
\text { Design } 2^{\| \prime}\end{array}$} \\
\hline & & & CD4+ & CD8+ & $\mathbf{A b}$ & CD4+ & CD8+ & $\mathbf{A b}$ \\
\hline GK1.5 & L3T4 & CD4 & - & + & - & - & + & + \\
\hline 2.43 & Lyt2 & CD8 & + & - & + & + & - & + \\
\hline Both & Both & Both & - & - & - & - & - & + \\
\hline HB151 & HLA-Dr5* & None & + & + & + & + & + & + \\
\hline
\end{tabular}

* Irrelevant control. ${ }^{*}$ This table represents a conceptual review of which elements in the immune response have been preserved $(+)$ or depleted (-). CD4+, CD4-postive lymphocytes; CD8+, CD8-positive lymphocytes; Ab, RSV-specific antibody. Depletion of a T lymphocyte subset resulted in $<1 \%$ positivity by FACS ${ }^{\oplus}$ in peripheral blood mononuclear cells. Otherwise the percentage of CD8-positive lymphocytes was $8.2 \pm 2.7 \%$ and that of CD4-positive lymphocytes was $27.0 \pm 8 \%$. When present at the time of rechallenge, the $\log _{2}$ reciprocal dilution antibody titers were $12.9 \pm 1.2$ by ELISA to $F$ and $7.0 \pm 0.3$ by plaque reduction neutralization. If antibody is indicated to be absent at the time of rechallenge the titer by ELISA to F was $<8.3$ and by neutralization was $<3.3$. Although there was no RSV-specific antibody detected in mice at the time of primary infection, a "+" denotes the potential for antibody response in that group. ${ }^{8}$ Immunodepletion initiated before primary infection and maintained through rechallenge period. "Immunodepletion initiated immediately before rechallenge.

the irrelevant control HB151. Mice were injected with $100 \mu \mathrm{g}$ of the appropriate monoclonal antibody intraperitoneally on three successive days. Thereafter, maintenance injections of $250 \mu \mathrm{g}$ of monoclonal antibody were given weekly. Efficacy of these treatments was determined by FACS analysis of heparinized whole blood using FITC or phycoerythrin-conjugated rat anti-mouse antibody to CD8 or CD4, respectively (Becton Dickinson, Mountainview, CA). Each antibody conjugate was incubated with $200 \mu \mathrm{l}$ of whole blood for $60 \mathrm{~min}$ at $37^{\circ} \mathrm{C}$. The red blood cells were lysed with a buffered $\mathrm{NH}_{4} \mathrm{Cl}$ solution and the remaining lymphocytes were washed twice then resuspended in PBS containing 5\% FBS before analysis on a Coulter Corp. Epic 753 FACS (Hialeah, FL).

Mouse infection and killing. Anesthetized mice were infected nasally with $100 \mu \mathrm{l}$ of undiluted stock virus as previously described (1). A clinical illness grading scale was derived by assigning numbers to a set of clinical features seen in mice with different degrees of illness: 0 , healthy; 1 , barely ruffled; 2 , ruffled, but active; 3 , ruffled and inactive; 4, ruffled, inactive, hunched, and gaunt; 5, dead. Mice were killed and tissue samples handled as previously described (1).

Viral quantitation and neutralization tests. Plaque assays for viral quantitation and plaque-reduction neutralization were performed as previously described (1).

$F$ ELISA. Immunoaffinity purified $\mathrm{F}$ and $\mathrm{G}$ glycoproteins of RSV and normal Vero cell lysates were a gift from Praxis Biologics, Rochester, NY. F or $\mathrm{G}$ was diluted to $200 \mathrm{ng} / \mathrm{ml}$ in Carbonate buffer (pH 9.6). $100 \mu \mathrm{l}$ of $\mathrm{F}$ or $\mathrm{G}$ suspension was applied to the antigen positive wells of Immunlon II 96-well plates (NUNC, Roskilde, Denmark) and normal Vero cell lysate was applied to the antigen-negative wells in a similar concentration. The performance of the assay has been previously described in detail (2).

\section{Results}

Experimental design and immune status of treatment groups. In the first design, mice were treated with three daily intraperitoneal injections of the monoclonal antibody immunodepletion regimen immediately before primary nasal infection with RSV. Maintenance injections of the appropriate MAb were given weekly to mice until the time of death. Mice were killed on days $4,5,7,11$, or 14 after primary infection, or were rechallenged with RSV after $28 \mathrm{~d}$ and killed $3 \mathrm{~d}$ later. At the time of rechallenge these groups varied in their capacity to produce RSV-specific antibody (Table I). GK1.5-treated mice had no
CD4+ lymphocytes and no RSV-specific antibody; anti-Lyt2treated mice had no CD8+ lymphocytes, but had normal immune levels of RSV-specific antibody; mice treated with both had no CD4+ or CD8+ lymphocytes and no RSV-specific antibody; HB151-treated mice had normal levels of CD4+ and CD8+ lymphocytes and had RSV-specific antibody. In the second design, normal mice were first infected with RSV, then immediately before rechallenge on day 28 , mice were treated with three daily injections of GK1.5, 2.43, both, or the control HB151. Mice in these groups were thereby rechallenged in the presence of RSV-specific antibody, and only lacked the T lymphocyte subset(s) depleted (Table I).

\section{Primary infection with $R S V$}

We first asked how the kinetics of terminating RSV replication after primary infection would be affected after depleting the CD4+ or CD8+ lymphocyte subset, and whether depletion of CD4+ or CD8+ lymphocytes would affect illness caused by primary RSV infection in mice.

$R S V$ replication in lung. The most discriminating timepoint for determining the kinetics of RSV replication in lung is day 7 after primary infection. On day 6 after primary infection, RSV titers in lung are near their peak, yet RSV can not be

Table II. RSV Replication in Lung after Primary Infection of Immunodepleted Mice*

\begin{tabular}{cccccc}
\hline & \multicolumn{5}{c}{ Geometric mean titers } \\
\cline { 2 - 6 } $\begin{array}{c}\text { Lymphocyte } \\
\text { subset } \\
\text { depleted }\end{array}$ & day 4 & day 5 & day 7 & day 11 & day 14 \\
\cline { 2 - 6 } & RSV in lung $\left(\log _{10}\right.$ pfu/g) \pm standard deviation \\
\hline CD4 & $7.2 \pm 0.2$ & $6.4 \pm 0.2$ & $5.5 \pm 0.4$ & $<1.8$ & $2.5(1 / 4)^{\ddagger}$ \\
CD8 & $7.0 \pm 0.1$ & $6.1 \pm 0.3$ & $5.7 \pm 0.4$ & $<1.8$ & $<1.8$ \\
Both & $7.1 \pm 0.1$ & $6.7 \pm 0.4$ & $6.4 \pm 0.2$ & $4.7 \pm 0.4$ & $4.4 \pm 0.2$ \\
None & $7.0 \pm 0.2$ & & $4.0 \pm 0.2$ & & $<1.8$ \\
\hline
\end{tabular}

* Data for days 4, 7 and 14 and for days 5 and 11 are from two separate experiments using five mice in each group. ${ }^{\ddagger}$ Only one of four remaining mice in this group had RSV isolated from lung. 


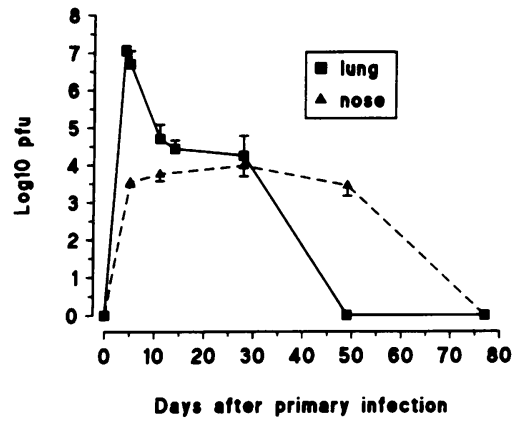

detected on day 8 in the lungs of normal mice (1). Termination of RSV replication in control mice treated with HB151 was similar to historical controls. The day 7 geometric mean RSV titer in lungs of HB151-treated control mice was $3.96 \log _{10} \mathrm{pfu} /$ g. Mice depleted of CD4+ or CD8+ lymphocytes had 1.5 or 1.8 $\log _{10} \mathrm{pfu} / \mathrm{g}$ higher RSV titers in lungs at day 7 than HB151treated controls $(P<0.0002$ and $<0.0001$ by two-tailed $t$ test, respectively) (Table II). When both CD4+ and CD8+ lymphocyte subsets were depleted, RSV replication was markedly prolonged. RSV titers in lungs of mice depleted of both CD4+ and CD8+ lymphocytes remained near their peak on day 7 $\left(6.35 \pm 0.15 \log _{10} \mathrm{pfu} / \mathrm{g}\right)$, and RSV was isolated from lung until day 28 (Table II, Fig. 1).

$R S V$ replication in nose. RSV replication in the nose of normal mice is also terminated by day 8 (1). In mice depleted of CD8+ lymphocytes, there was evidence that RSV replication in nose was prolonged. RSV was recovered from nose in two of five CD8-depleted mice at day 11 (Table III). In mice depleted of both CD4+ and CD8+ lymphocytes, RSV titers in nose remained near their peak beyond day 11 , and RSV was isolated from nose up to $49 \mathrm{~d}$ after primary infection (Fig. 1).

Illness. The degree of illness was assessed by weight change and by a clinical illness score assigned by a blinded observer. Illness after primary infection was partially diminished by CD4+ lymphocyte depletion, but was diminished to a greater extent by CD8+ lymphocyte depletion (Figs. 2 and 3). There

Table III. RSV Replication in Nose after Primary Infection of Immunodepleted Mice*

\begin{tabular}{ccc}
\hline & \multicolumn{2}{c}{ Geometric mean titers } \\
\cline { 2 - 3 } $\begin{array}{c}\text { Lymphocyte } \\
\text { subset } \\
\text { depleted }\end{array}$ & \multicolumn{2}{c}{ RSV in nose $\left(\log _{10}\right.$ pfu/nose $)$} \\
\cline { 2 - 3 } CD4 & day 5 & day 11 \\
CD8 & $3.5 \pm 0.1$ & $<1.1$ \\
Both & $3.6 \pm 0.1$ & $1.4(2 / 5)^{\ddagger}$ \\
& $3.5 \pm 0.1$ & $3.8 \pm 0.2$
\end{tabular}

* Nose titers of RSV expressed as $\log _{10}$ pfu/nose in immunodepleted mice after primary infection. These mice are the same as those represented from day 5 and 11 in Table II. ${ }^{\ddagger}$ If RSV was not isolated from all mice, numbers in parentheses represent proportion of mice from which virus was isolated.

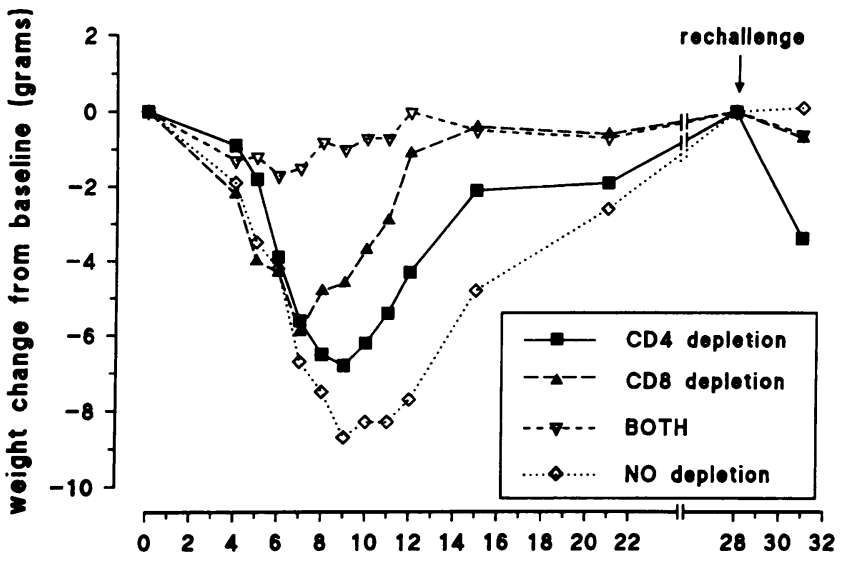

Days After Primary Infection

Figure 2. This graph depicts weight loss in mice after primary RSV infection and rechallenge after differential depletion of CD4, CD8, both, or neither $\mathrm{T}$ lymphocyte subset using design 1 .

was a striking lack of illness caused by primary RSV infection in mice with both CD4+ and CD8+ lymphocyte subsets depleted. Despite prolonged high titer RSV replication in lung, mice depleted of both lymphocyte subsets had virtually no weight loss and showed no clinical signs of illness. We next asked how the histologic patterns in lung correlated with the termination of RSV replication and illness after primary infection in mice.

Histology. In HB151-treated normal control mice the histologic appearance of lungs after primary infection included infiltration of lymphoid and monocytoid cells around the bronchovascular bundles, and an increase in alveolar lymphocytes and macrophages on day 7 (Fig. $4 \mathrm{D}$ ), followed by a collection of uniform, small, basophilic lymphocytes that formed small aggregates around the bronchovascular bundles during convalescence. In mice depleted of both CD4+ and CD8+ lymphocyte subsets there was virtually no lymphocyte response in lungs after primary infection (Fig. $4 C$ ). In mice depleted of CD8+ lymphocytes there was an infiltrate of lymphocytes around the

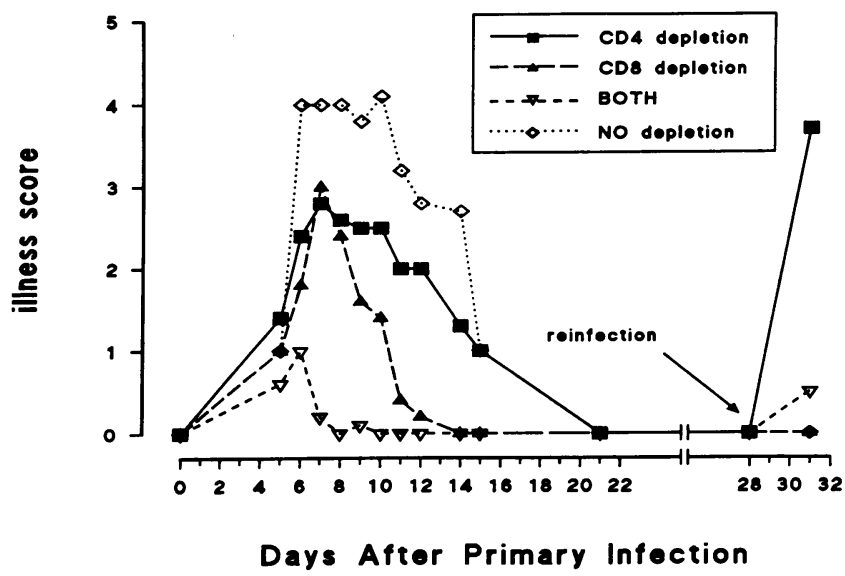

Figure 3. This graph depicts clinical illness scores in mice after primary RSV infection and rechallenge after differential depletion of CD4, CD8, both, or neither T lymphocyte subset using design 1 . 

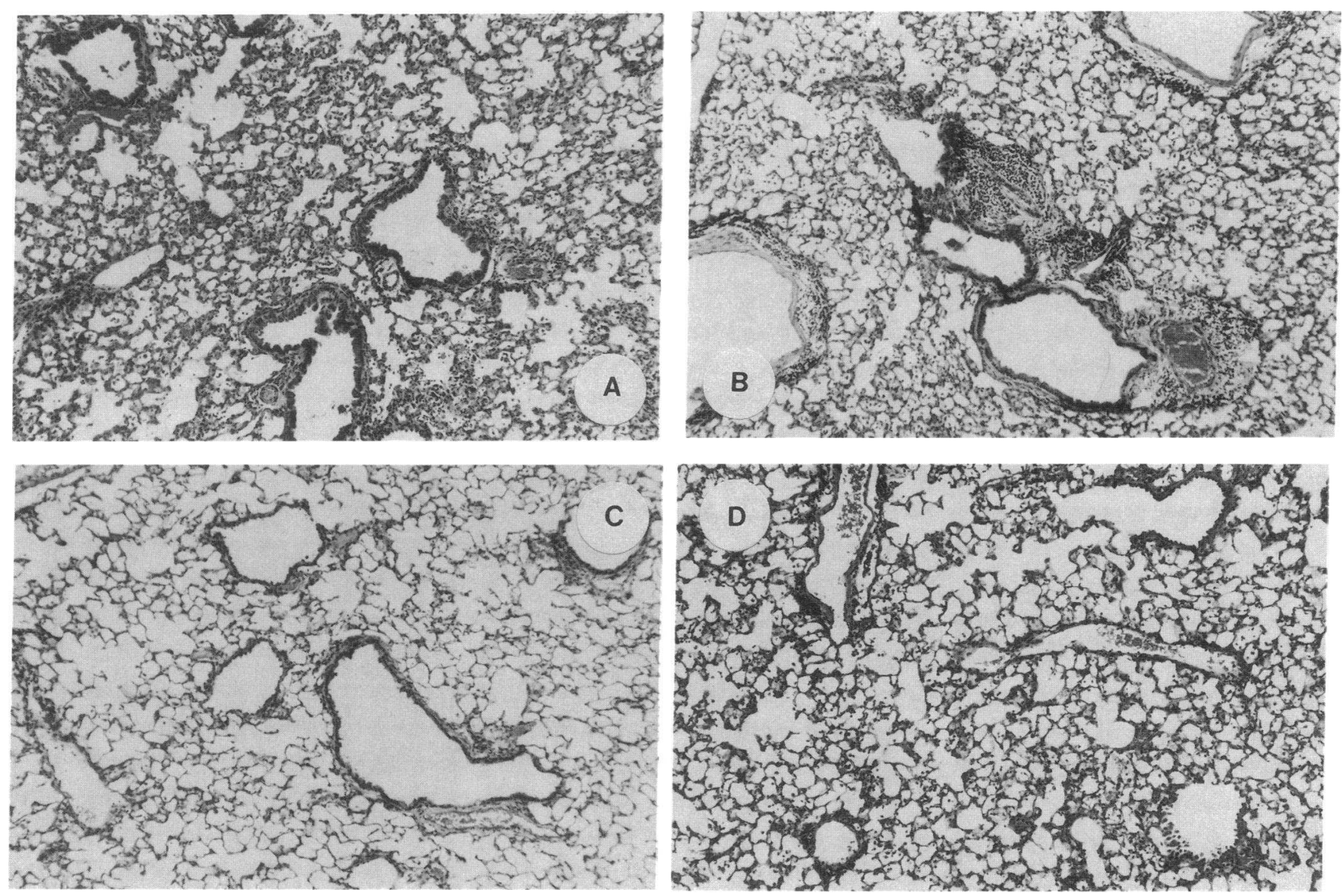

Figure 4. Lung photomicrographs from mice on day 7 after primary RSV infection during which CD4 $(A)$, CD8 $(B)$, both $(C)$, or neither $(D)$ T lymphocyte subset was depleted.

bronchovascular structures, and a moderate increase in alveolar lymphocytes (Fig. 4 B). CD4+ lymphocyte depleted mice had relatively few lymphocytes in the bronchovascular spaces compared to CD8-depleted mice or HB151-treated controls, but had substantial increases in alveolar lymphocytes (Fig. 4 A). CD4-depleted mice also lacked peribronchovascular lymphocytic aggregates during convalescence from primary infection.

From these studies we concluded that both CD4+ and CD8+ lymphocytes were important for terminating RSV replication after primary infection and that both subsets contributed to the pathogenesis of illness caused by primary RSV infection.

\section{Rechallenge of mice with RSV}

We next asked whether depletion of CD4+ or CD8+ lymphocytes would influence protection upon rechallenge with RSV. Rechallenge of mice was performed in two distinct immunologic settings as explained above (Table I). In normal untreated mice rechallenged $4 \mathrm{wk}$ after primary infection, no RSV can be isolated from lungs or noses at day 3 and no illness occurs (2).

Replication of $R S V$ in lungs. In mice rechallenged using design 1 (continuous depletion) and depleted of CD4+ lymphocytes, high titers of RSV were isolated from lung, but were 1.0 to $1.5 \log _{10} \mathrm{pfu} / \mathrm{g}$ lower than would be expected in primary infection (Table IV). In mice depleted of CD8 + lymphocytes using design 1, no RSV was detected in lungs of rechallenged mice. Mice depleted of both CD4+ and CD8+ lymphocytes using design 1, attained RSV titers in lung after rechallenge that were comparable to those seen in primary infection. When mice were rechallenged in the presence of RSV-specific antibody using design 2 (depletion immediately before rechallenge) the outcome of rechallenge was much different (Table V). Regardless of which lymphocyte subset was depleted, RSV replication was markedly diminished when rechallenge occurred in the presence of RSV-specific antibody. No RSV was isolated from lungs of mice treated with GK1.5 or from HB151-treated controls. Low titers of RSV were isolated from lungs in only 3 of 11 mice depleted of CD8+ lymphocytes before rechallenge and in only 5 of 11 mice depleted of both CD4+ and CD8+ lymphocytes before rechallenge.

$R S V$ replication in nose. In mice depleted of CD4+ lymphocytes using design 1, RSV was isolated from the noses of all mice $3 \mathrm{~d}$ after rechallenge. RSV was isolated in only 1 of 10 mice depleted of CD8+ lymphocytes using design 1. Depleting both the CD4+ and CD8+ lymphocytes using design 1 permitted replication of RSV in nose to titers comparable to primary infection. There was no RSV isolated from the noses of HB151-treated rechallenged mice. In mice rechallenged using design 2, RSV was recovered from 7 of 11 and 8 of 11 noses in groups depleted of CD8+ lymphocytes and both CD4+ and CD8+ lymphocytes, respectively. This is in contrast to the HB151-treated controls in which no RSV was isolated from nose, and mice depleted of CD4+ lymphocytes in which RSV 
Table IV. Replication of RSV in Lung and Nose after Rechallenge of Mice Immunodepleted Throughout Primary Infection and Rechallenge (Design 1) or Immunodepleted Just before Rechallenge (Design 2)*

\begin{tabular}{|c|c|c|c|c|}
\hline \multirow{4}{*}{$\begin{array}{l}\text { Lymphocyte } \\
\text { subset depleted }\end{array}$} & \multicolumn{4}{|c|}{ Geometric mean titers } \\
\hline & \multicolumn{4}{|c|}{$\log _{10} \mathrm{pfu} / \mathrm{g}$ lung or per nose } \\
\hline & \multicolumn{2}{|c|}{ Design 1} & \multicolumn{2}{|c|}{ Design 2} \\
\hline & Lung & Nose & Lung & Nose \\
\hline CD4 & $5.1 \pm 0.7$ & $1.4 \pm 0.3(11 \text { of } 11)^{\ddagger}$ & $<1.8$ & $1.1(1 \text { of } 11)^{\ddagger}$ \\
\hline CD8 & $<1.8$ & $1.8(1$ of 10$)$ & $2.0(3$ of 11$)$ & $1.7(7$ of 11$)$ \\
\hline Both & $6.4 \pm 0.5$ & $3.9 \pm 0.5(11$ of 11$)$ & $2.5(5$ of 11$)$ & $1.9(8$ of 11$)$ \\
\hline None & $<1.8$ & $<1.1$ & $<1.8$ & $<1.1$ \\
\hline
\end{tabular}

* Mice were killed on day 3 after rechallenge. The data represent the combined results of two separate experiments with a total of 11 mice in each group. In design $1 \mathrm{MAb}$ treatment was initiated before primary infection and maintained through the rechallenge. In design $2 \mathrm{MAb}$ treatment was initiated $3 \mathrm{~d}$ before rechallenge. ${ }^{\ddagger}$ Numbers in parentheses represent proportion of mice from which virus was isolated. If not indicated, virus was isolated from all or none of the mice.

was isolated from only 1 of 11 noses. These data suggest a potential role for CD8 lymphocytes in mucosal immunity.

Illness. Mice depleted of CD4 lymphocytes using design 1 had severe illness after rechallenge (Figs. 2 and 3). Mice depleted of CD8, both, or HB151-treated controls in design 1 did not exhibit illness (Figs. 2 and 3). Similarly, there was no illness in rechallenged mice using design 2 in which mice were rechallenged in the presence of RSV-specific antibody, but with CD4, CD8, or both lymphocyte subsets depleted. Therefore, illness after rechallenge only occurred in the setting in which CD8+ lymphocyte responses were intact, in the presence of replicating virus, and in the absence of RSV-specific antibody (Figs. 2
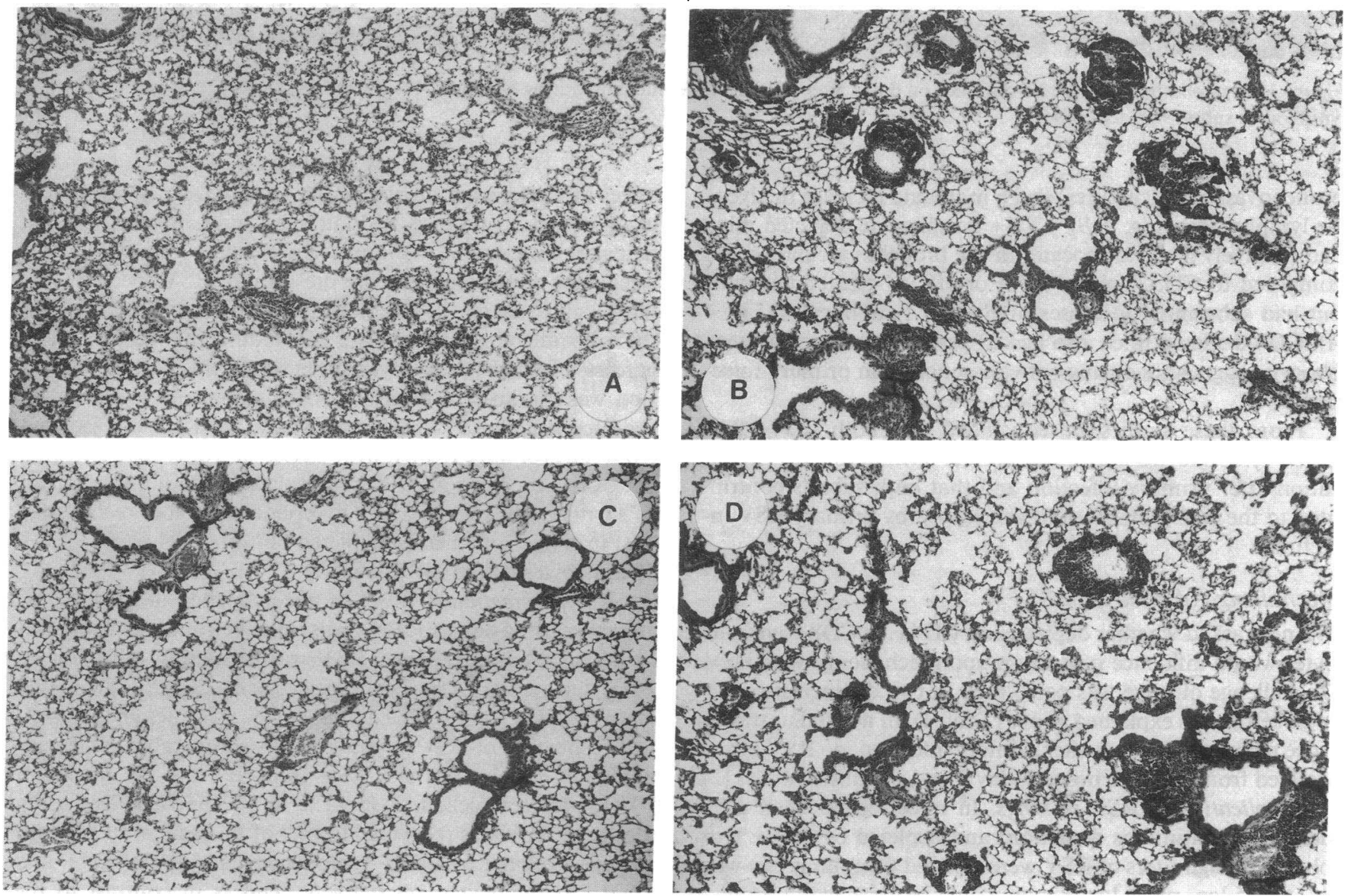

Figure 5. Lung photomicrographs from mice on day 3 after RSV rechallenge using design 1 in which CD4 $(A)$, CD8 $(B)$, both $(C)$, or neither $(D)$ $T$ lymphocyte subset was depleted before primary infection and depletion maintained through the rechallenge period. 
and 3). We next asked how the histologic patterns in lung correlated with protection from reinfection and illness after rechallenge.

Histology. Upon rechallenge, distinct differences in the histological patterns between groups were more clearly discernable than after primary infection. Depletion of CD4+ lymphocytes using either design 1 or design 2 is associated with the absence of peribronchovascular lymphocytic aggregates after rechallenge (Figs. $5 A$ and $6 A$ ). In design 1, CD4-depleted mice, there was a marked increase in the presence of alveolar lymphocytes (Fig. $5 \mathrm{~A}$ ), which was associated with RSV replication, the presence of CD8+ lymphocytes, the absence of RSVspecific antibody, and severe illness. In design 2, CD4-depleted mice, alveolar lymphocytes were not present (Fig. $6 A$ ). In both design 1 and design 2, CD8-depleted mice had prominent peribronchovascular lymphocytic aggregates after rechallenge (Figs. $5 \mathrm{~B}$ and $6 \mathrm{~B}$ ), suggesting that $\mathrm{CD} 8+$ lymphocytes were not necessary for this response. Mice depleted of both CD4+ and CD8+ lymphocytes did not have significant numbers of peribronchovascular or alveolar lymphocytes present (Figs. $5 C$ and $6 C$ ). In rechallenged HB151-treated normal control mice, histologic examination demonstrated an expansion of the peribronchovascular lymphocytic aggregates seen during convalescence (Figs. $5 \mathrm{D}$ and $6 \mathrm{D}$ ). The immunodepletion experiments therefore suggest that the peribronchovascular lymphocytic aggregates require the presence of CD4+ lymphocytes, and that alveolar lymphocytes are a correlate of illness. In mice with
CD4+ lymphocytes present at the time of rechallenge, whether $\mathrm{CD} 8+$ lymphocytes were depleted (Figs. $5 B$, and $6 B$ ) or mice were normal (Figs. $5 D$ and $6 D$ ), the formation of the peribronchovascular lymphocytic aggregates occurred despite no recovery of RSV from the lungs on day 3 after rechallenge. This implies only limited RSV replication or nonreplicating RSV antigen alone was required to induce the response.

We concluded from the rechallenge experiments that RSVspecific antibody responses were necessary for complete protection from RSV replication in lungs after rechallenge. This was compatible with data derived from experiments in anti- $\mu$ treated mice in which rechallenged mice were only partially protected from RSV replication in lungs in the absence of $B$ cells (2a). There was also a suggestion that CD8+ lymphocytes were involved in limiting RSV replication in nose based on the data presented in Table IV. Finally, CD8 + lymphocytes seemed to be an important determinant of illness in the rechallenge setting in which RSV-specific antibody was absent.

\section{Discussion}

Approaches to understanding the specific role of individual components of the immune response are emerging with the availability of reagents that can selectively delete biological functions. We have applied strategies employed in tissue rejection systems and other virus infection models to investigate the immunopathogenesis of RSV infection in mice. These studies
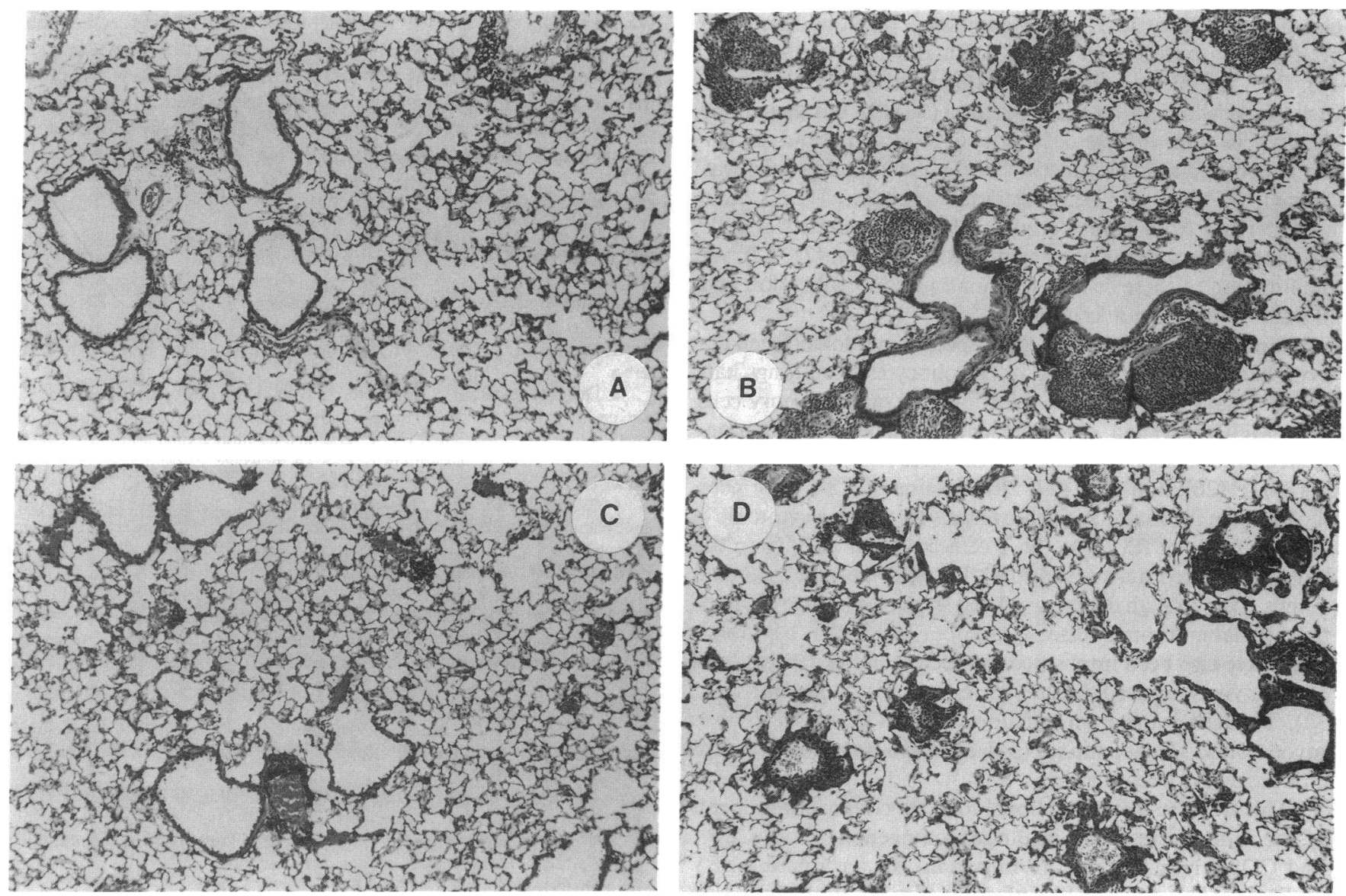

Figure 6. Lung photomicrographs from mice on day 3 after RSV rechallenge using design 2 in which CD4 $(A)$, CD8 $(B)$, both $(C)$, or neither $(D)$ T lymphocyte subset was depleted immediately before rechallenge. 
were based on the ability of particular monoclonal antibodies directed at lymphocyte surface determinants to deplete or interfere with the function of targeted lymphocyte populations in vivo. The monoclonal antibodies, GK 1.5 and 2.43 , are rat $\mathrm{IgG}_{2 \mathrm{~b}}$ directed against L3T4 (murine CD4) and Lyt2 (murine CD8), respectively (5). Another rat $\mathrm{IgG}_{2 \mathrm{~b}}$ monoclonal antibody, HB151, directed at the human HLA-Dr5 determinant was used as an irrelevant control. It has been demonstrated in tissue rejection systems $(6,7)$, models of autoimmunity $(8)$, and infection systems for viruses $(9-13)$ and parasites $(14,15)$ that in vivo CD4+ or CD8+ lymphocyte subset depletion as measured by FACS $^{\otimes}$ and functional assays can be accomplished using monoclonal antibodies directed at lymphocyte surface determinants. The value of this approach in providing relevant data about the functional role of lymphocyte subsets in pathogenesis of virus infections has been best demonstrated in the lymphocytic choriomeningitis virus (LCMV) system. The LCMV mouse model has been a prototype for the delineation of lymphocyte function in viral clearance and pathogenesis of disease. The functional role of lymphocyte subsets in LCMV pathogenesis has been investigated using the in vivo MAb immunodepletion approach, and has been found to accurately reflect what had been learned from in vitro functional lymphocyte studies and adoptive transfer experiments $(10,11,13)$.

The importance of the cell-mediated immune response in human disease caused by RSV is still unclear. RSV-infected children with prolonged viral shedding, severe disease, and giant cell pneumonia have not had isolated cell-mediated deficiencies, but have had severe combined immunodeficiency syndrome with deficits in both $\mathrm{T}$ cell and $\mathrm{B}$ cell functions (16, 17). RSV-specific lymphocyte proliferation has been detected in normal children after RSV infection $(18,19)$, but there is no clear correlation with age or severity of disease (18) and neither the phenotype nor the function of the proliferating cells was defined. RSV-specific HLA-restricted cytotoxic T cells have been derived from adult peripheral blood mononuclear cells (20) and from children after acute RSV infection $(21,22)$, yet the function of these cells in terminating RSV replication and in pathogenesis is not known.

In mice, MHC-restricted RSV-specific cytotoxic T cell activity has been demonstrated in lymphocytes from lungs harvested 7 days after primary infection (23), and memory cells with MHC-restricted cytotoxic activity have been demonstrated in the spleens of convalescent mice (24). Since then the $\mathrm{N}(25), \mathrm{F}(26)$, and $22 \mathrm{~K}(27,28)$ proteins of RSV have been shown to be the major antigenic targets for murine cytotoxic $T$ cells. Transfer of RSV-specific T cells can clear RSV from the lungs of infected nu/nu mice (29), but RSV-specific cytotoxic $T$ cells given in high doses have been shown to induce a potentially lethal pulmonary disease in mice (30). CD8 + T lymphocytes have also been implicated as effectors in the pathogenesis of other virus-induced diseases including LCMV cerebritis (31, 32), Theiler's murine encephalomyelitis (13), coxsackievirus myocarditis (33), hepatitis A (34), and type B or non-A, non-B chronic active hepatitis (35).

This study suggests functional roles for certain components of the immune response in illness pathogenesis. Both CD4+ and CD8+ lymphocytes are important for terminating RSV replication in primary RSV infection of mice. Both $\mathrm{T}$ cell subsets also contribute to illness in primary RSV infection of mice, although CD8+ lymphocytes appear to be the more important mediator of illness. Deleting the CD8+ lymphocyte population in mice during primary infection resulted in modest illness and early recovery. Anderson et al. recently published work supporting the conclusion that $\mathrm{CD} 8+$ lymphocytes play a role in the illness after primary infection in mice. MHC class I-restricted cytotoxic $\mathrm{T}$ cell activity was optimal in lung lymphocytes from mice between 7 and $9 \mathrm{~d}$ after primary RSV infection (36), which corresponds to the peak of illness following primary infection in mice. In our study, rechallenged mice in which CD8+ lymphocytes were present, but CD4+ lymphocytes and RSV-specific antibody were absent, severe illness occurred, again implicating CD8+ lymphocytes as an important mediator of illness.

This work together with data from anti- $\mu$ treated mice (2a), supports a general theme of antibody being a safe (illness-sparing) mechanism of protection from RSV infection in mice, and T lymphocytes (CD8+ > CD4+) being an important determinant of illness. The balance of the triad: RSV replication, RSVspecific antibody, and RSV-specific CD8 + lymphocytes, is at least one determinant of illness in primary infection and reinfection of mice with RSV. Only in the setting of significant RSV replication, a CD8+ lymphocyte response, and the absence of antibody was illness manifest to the fullest extent in mice after primary infection or rechallenge. Further definition of immune responses that induce illness in RSV-infected mice may enhance the development of a safe, effective vaccine for use in man.

\section{Acknowledgments}

We thank Drs. Martin Blaser, Daniel Colley, and Alexander Lawton for reviewing the manuscript and Ms. Mentoria Jennings for secretarial assistance. Dr. Graham was an American College of Physicians Teaching and Research Scholar during a portion of the work.

This work was supported by funding from the World Health Organization, and in part by NIH contract NO1-AI-52576.

\section{References}

1. Graham, B. S., M. D. Perkins, P. F. Wright, and D. T. Karzon. 1988 Primary respiratory syncytial virus infection in mice. J. Med. Virol. 26:153-162. 2. Graham, B. S., L. A. Bunton, P. F. Wright, and D. T. Karzon. 1991. Reinfection of mice with respiratory syncytial virus. J. Med. Virol. 34:7-13.

2a. Graham, B. S., L. A. Bunton, J. Rowland, P. F. Wright, and D. T. Karzon. 1991. Respiratory syncytial virus infection in anti- $\mu$ treated mice. $J$. Virol. In press.

3. Dialynas, D. P., Z. S. Quan, K. A. Wall, A. Pierres, J. Quintanes, M. R Loken, M. Pierres, and F. W. Fitch. 1983. Characterization of the murine T cell surface molecule, designated L3T4, identified by monoclonal antibody GK1.5: similarity of L3T4 to the human LEU-3/T4 molecule. J. Immunol. 131:24452451 .

4. Sarmiento, M., A. L. Glasebrook, and F. W. Fitch. 1980. IgG or IgM monoclonal antibodies reactive with different determinants on the molecular complex bearing Lyt- 2 antigen block $\mathrm{T}$ cell-mediated cytolysis in the absence of complement. J. Immunol. 125:2665-2672.

5. Dialynas, D. P., D. B. Wilde, P. Marrack, A. Pierres, K. A. Wall, W. Harvan, G. Otten, M. R. Loken, M. Pierres, J. Kappler, and F. W. Fitch. 1983. Characterization of the murine antigenic determinant, designated L3T4a, recognized by monoclonal antibody GK1.5: expression of L3T4a by functional T cell clones appears to correlate primarily with class II MHC antigen-reactivity. Immunol. Rev. 74:30-56.

6. Cobbold, S. P., G. Martin, S. Qin, and H. Waldmann. 1986. Monoclonal antibodies to promote marrow engraftment and tissue graft tolerance. Nature (Lond.). 323:164-166.

7. Cobbold, S. P., and Waldman H. 1986. Skin allograft rejection by L3T4+ and Lyt2+ T cell subsets. Transplantation. 41:634-639.

8. Wofsy, D., and W. E. Seaman. 1985. Successful treatment of autoimmunity in NZB/NZW $F_{1}$ mice with monoclonal antibody to L3T4. J. Exp. Med. $161: 378-391$

9. Jamieson, B. D., B. D. Butler, and R. Ahmed. 1987. Effective clearance of a persistent viral infection requires cooperation between virus-specific Lyt $2+T$ cells and nonspecific bone marrow-derived cells. J. Virol. 61:3930-3937. 
10. Leist, T. P., S. P. Cobbold, H. Waldman, M. Aguet, and R. M. Zinkernagel. 1987. Functional analysis of T lymphocyte subsets in antiviral host defense. $J$. Immunol. 138:2278-2281.

11. Lightman, S., S. Cobbold, H. Waldmann, and B. A. Askonas. 1987. Do L3T4 $\mathrm{T}$ cells act as effector cells in protection against influenza virus infection? Immunology. 62:139-144.

12. Moskophidis, D., S. P. Cobbold, H. Waldmann, and F. Lehmann-Grube. 1987. Mechanism of recovery from acute virus infection: Treatment of lympho cytic choriomeningitis virus-infected mice with monoclonal antibodies reveals that Lyt $2+\mathrm{T}$ lymphocytes mediate clearance of virus and regulate the antivira antibody response. $J$. Virol. 61:1867-1874.

13. Rodriguez, M., and S. Sriram. 1988. Successful therapy of Theiler's virusinduced demyelination (DA strain) with monoclonal anti-Lyt2 antibody. J. Im munol. 140:2950-2955.

14. Katona, I. M., J. F. Urban, and F. D. Finkelman. 1988. The role of L3T4 and Lyt $2 \mathrm{~T}$ cells in the IgE response and immunity to Nippostrongylus brasiliensis. J. Immunol. 140:3206-3211.

15. Kelley, E. A. B., and D. G. Colley. 1988. In vivo effects of monoclonal anti-L3T4 antibody on immune responsiveness of mice infected with Schistosoma mansoni: reduction of irradiated cercariae-induced resistance. J. Immunol. 140:2737-2745.

16. Fishaut, M., D. Tubergen, and K. McIntosh. 1980. Cellular response to respiratory viruses with particular reference to children with disorders of cell-mediated immunity. J. Pediatr. 96:179-186.

17. Milner, M. E., S. D. L. Monte, and G. M. Hutchins. 1985. Fatal respiratory syncytial virus infection in severe combined immunodeficiency syndrome. Am. J. Dis. Child. 139:1111-1114.

18. Scott, R., C. R. Pullan, J. McQuillan. 1984. Cell-mediated immunity in respiratory syncytial virus disease. J. Med. Virol. 13:105-114.

19. Welliver, R. C., A. Kaul, and P. L. Ogra. 1979. Cell-mediated immune response to respiratory syncytial virus infection: relationship to the developmen of reactive airway disease. J. Pediatr. 94:370-375.

20. Bangham, C. R. M., and A. J. McMichael. 1986. Specific human cytotoxic $T$ cells recognize B-cell lines persistently infected with respiratory syncytial virus. Proc. Natl. Acad. Sci. USA. 83:9183-9187.

21. Issacs, D., C. R. M. Bangham, and A. J. McMichael. 1987. Cell-mediated cytotoxic response to respiratory syncytial virus in infants with bronchiolitis. Lancet. ii:769-771.

22. Chiba, Y., Y. Higashidate, K. Suga, K. Honjo, H. Tsutsumi, and P. L. Ogra. 1989. Development of cell-mediated cytotoxic immunity to respiratory syncytial virus in human infants following naturally acquired infection. $J$. Med. Virol. 28:133-139.

23. Taylor, G., E. J. Scott, and A. J. Hayle. 1985. Cytotoxic lymphocytes in the lungs of mice infected with respiratory syncytial virus. J. Gen. Virol. 66:25332538.
24. Bangham, C. R. M., M. J. Cannon, D. T. Karzon, and B. A. Askonas. 1985. Cytotoxic T-cell response to respiratory syncytial virus in mice. J. Virol. 56:55-59.

25. Bangham, C. R. M., P. J. M. Openshaw, L. A. Ball, A. M. Q. King, G. W. Wertz, and B. A. Askonas. 1986. Human and murine cytotoxic $T$ cells specific to respiratory syncytial virus recognize the viral nucleoprotein $(N)$, but not the major glycoprotein $(G)$, expressed by vaccinia virus recombinants. J. Immunol. 137:3973-3977.

26. Pemberton, R. M., M. J. Cannon, P. J. M. Openshaw, L. A. Ball, G. W Wertz, and B. A. Askonas. 1987. Cytotoxic T cell specificity for respiratory syncytial virus proteins: fusion protein is an important target antigen. J. Gen. Virol. 68:2177-2182

27. Openshaw, P. J. M., K. Anderson, G. W. Wertz, and B. A. Askonas. 1990. The 22,000-dalton protein of respiratory syncytial virus is a major target for $\mathrm{K}^{\mathrm{d}}$-restricted cytotoxic $\mathrm{T}$ lymphocytes from mice primed by infection. $J$. Virol. 64:1683-1689.

28. Nicholas, J. A. K. L. Rubino, M. E. Levely, E. G. Adams, and P. L. Collins. 1990. Cytolytic T-lymphocyte responses to respiratory syncytial virus: effector cell phenotype and target proteins. J. Virol. 64:4232-4241.

29. Cannon, M. J., E. J. Stott, G. Taylor, and B. A. Askonas. 1987. Clearance of persistent respiratory syncytial virus infections in immunodeficient mice following transfer of primed T cells. Immunology. 62:133-138.

30. Cannon, M. J., P. J. M. Openshaw, and B. A. Askonas. 1988. Cytotoxic T cells clear virus but augment lung pathology in mice infected with respiratory syncytial virus. J. Exp. Med. 168:1163-1168.

31. Allan, J. E., and P. C. Doherty. 1985. Immune T cells can protect or induce fatal neurological disease in murine lymphocytic choriomeningitis. Cell. Immunol. 90:401-407.

32. Baenziger, J., H. Hengartner, R. M. Zinkernagel, and G. A. Cole. 1986. Induction or prevention of immunopathological disease by cloned cytotoxic $T$ cell lines specific for lymphocytic choriomeningitis virus. Eur. J. Immunol. 16:387-393.

33. Kishimoto, $C$., and W. H. Abelmann. 1990. In vivo significance of $T$ cells in the development of coxsackie B3 myocarditis in mice. Circ. Res. 67:589-598.

34. Vallbracht, A., K. Maier, Y. D. Stierhof, K. H. Wiedmann, B. Flehmig and B. Fleischer. 1989. Liver-derived cytotoxic T cells in hepatitis A virus infection. J. Infect. Dis. 160:209-217.

35. Monzón, C. G., R. M. Otero, J. M. Pajares, A. G. Sánchez, M. L. Botet, M. O. Landázuri, and F. S. Madrid. 1990. Expression of a novel activation antigen on intrahepatic CD8+ T lymphocytes in viral chronic active hepatitis. Gastroenterology. 98:1029-1035.

36. Anderson, J. J., J. Norden, D. Saunders, G. L. Toms, and R. Scott. 1990. Analysis of the local and systemic immune responses induced in BALB/c mice by experimental respiratory syncytial virus infection. J. Gen. Virol. 71:1561-1570. 